\title{
LITERARISCHE SUMPFLANDSCHAFTEN. TECHNISCHER FORTSCHRITT UND NATURGESTALTUNG BEI MÓR JÓKAI (1825-1904)
}

\author{
ENDRE HÁRS \\ University of Szeged \\ hars@lit.u-szeged.hu
}

\begin{abstract}
Der ungarische Romancier Mór (Maurus) Jókai (1825-1904) war in der Hinsicht sicherlich ein Schriftsteller der zweiten Hälfte des 19. Jahrhunderts, als er das Fortkommen der Nation mit auf die Technik und die Wissenschaft gerichteten Hoffnungen verband. In seinem über hundert Romane und Erzählungen umfassenden Lebenswerk wird unter anderem ein für das damalige Ungarn bedeutsames Spezialthema, die Hydrografie des 18. und 19. Jahrhunderts erfasst. Themen wie die Moorkolonisation, die Flussregulierung und die Melioration sind in verblüffend vielen Werken Jókais handlungsrelevant und entfalten darüber hinaus eine Ästhetik, die ihn zu einem besonderen Vertreter literarischer Topografien macht.
\end{abstract}

Schlüsselwörter: literarische Topografie, Geschichte der Hydrografie, Romanpoetik

Die literarischen Topografien stellen eine besondere Kategorie in der Wahrnehmung und Repräsentation von Landschaften dar. Ihr historischer Spielraum reicht von älteren, gattungsspezifischen Anwendungen bis hin zu umfassenden Konzeptualisierungen, von der themenbezogenen (Fach-)Literatur bis zur imaginär-poetischen Landschaftsdarstellung. Im Folgenden soll einem besonderen topografischen Thema und einer spezifischen (literatur-)historischen Konstellation nachgegangen werden: der belletristischen Verarbeitung der ungarischen Hydrografie des 18. und 19. Jahrhunderts. Sucht man nach Beispielen, Verlängerungen oder eben Verkürzungen der Themen ,Moorkolonisation', ,Flussregulierung' und ,Melioration', so rückt für den genannten Zeitraum das Schaffen des ungarischen Erfolgsautors Mór (Maurus) Jókai (1825-1904) in den Blick. Bei gezielter Suche in seinem über hundert Romane und Erzählungen umfassenden Lebenswerk - wozu auch noch Publizistik bzw. ethno- und kulturgeografische Schriften kommen - überrascht die thematische Frequenz von Fluss-, Teich- und Sumpflandschaften, deren Bedeutsamkeit für die literarische Öffentlichkeit der zweiten Hälfte des 19. Jahrhunderts auch hinsichtlich der Tatsache nicht zu ver- 
harmlosen ist, dass Jókais Werke in mehreren Sprachen Österreich-Ungarns bzw. Europas rezipiert wurden. Dabei fällt auf, dass die Behandlung des Themas in zahlreichen Texten des Autors deutlich mehr leistet als die Zurverfügungstellung romanhafter Schauplätze. Was hier erst einmal zu beweisen wäre.

Zur Charakterisierung Jókais empfiehlt es sich - da sonst auch deutschsprachige Forschungsliteratur vorliegt ${ }^{1}$ - nur so viel voranzuschicken, als zum Thema wirklich notwendig ist. Bezeichnenderweise hat die Kulturhistorikerin Anna Fábri 1991 den Ausdruck „Jókai-Ungarn“2 aufgegriffen, womit nicht nur gemeint war, dass das Werk des Romanciers ein spezifisches Bild des Landes vermittelte, sondern auch, dass darin das Ungarn des 19. Jahrhunderts in historisch-politischer, sozio-kultureller und auch natur- und technikgeschichtlicher Komplexität erfasst wurde. ${ }^{3}$ Bei allem Vorbehalt, den die akademische Literaturkritik und -geschichtsschreibung Jókais literarischem Popularismus gegenüber vorgebracht hat, ${ }^{4}$ war die Reichweite seines Interesses an literarisch verwertbaren Themen und Stoffen auch gedacht als Arbeit am historisch-kulturellen Gedächtnis einer - traumatisierten (1848/49) bzw. geblendeten (1867) - Nation. Zu diesem schriftstellerischen Projekt gehörten wiederum der Gestus der Erziehung für die $\mathrm{Zu}-$ kunft und Strategien der Vermittlung modernen Wissens. In Folge dessen gründete sich der Welt-Charakter seiner Romane - im Einzelnen und zusammengenommen - nicht nur auf eine spezifisch Jókaische poetische Gerechtigkeit, ${ }^{5}$ sondern auch auf die Liebe zum Detail ${ }^{6}$ (welcher Art auch immer). Und hierzu gehören auch die je nach literaturhistorischer Begriffsbildung romantisch oder realistisch genannten Schilderungen von Land- und Ortschaften, wobei Jókais Schauplätze sowohl symbolisch aufgeladen als auch mit historischen Informationen gefüttert sind, d.h. der erzählerischen Motivierung ebenso verpflichtet bleiben, wie der volkserzieherischen Absicht.

\section{Literarische Hydrografie}

Fokussiert man in diesem Reichtum auf die genannten thematischen Aspekte, so lässt sich leichterhand eine imaginäre Karte rekonstruieren, die man auch Jókais literarische Hydrografie Ungarns nennen könnte. Auf dieser Karte lassen sich all die Gewässer eintragen, die in seinen Geschichten eine Rolle spielen. Darüber hinaus, dass in Jókais Euvre, das ganz Ungarn durchstreift, selbstverständlich alle Flüsse, Teiche, Überschwemmungs- und Sumpfgebiete auftauchen, kann man diese Karte auch auf die Frequenz und die Funktion der Schauplätze hin prüfen, und besonders die Gewässer ins Auge fassen, die in vielen Texten und an markanten Stellen geschildert werden. In Hinsicht auf die thematische und/oder narrative Signifikanz - und sei sie nur von episodischer Relevanz - kann man von 'Donauromanen' sprechen, wie im Fall von Zoltán Kárpáthy (1854, dt. 1860), ${ }^{7}$ 
Ein Goldmensch (1872, dt. 1873), Der Roman des künftigen Jahrhunderts (187274, dt. 1879), Ein bejahrter Mann ist kein alter Mann (1900, dt. 1900). Auch kann man, wenn nicht gleich 'Theißromane', so doch zahlreiche, um die Theiß gelagerte Schauplätze finden, wie z.B. in den Romanen Lebenswirren (1846, dt. 1886), Der neue Gutsherr (1862, dt. 1871), Verkehrte Welt (1863, dt. 1873; 1884) und Die Kleinkönige (1885, dt. 1886). Und auch von anderweitigen Flusslandschaften, wie von der Drau in Die goldene Zeit in Siebenbürgen (1851, dt. 1872) und der Körös in Der Mann mit dem steinernen Herzen (1869, dt. 1885), sogar vom Roman des Neusiedlersees in Das namenlose Schloß (1877, dt. 1879) lässt sich behaupten, dass die Landschaftsbeschreibung mehr leistet als gewöhnliche Romanschauplätze. Die genannten Gewässer werden in ihrer historischen Lage und Umgebung dargestellt, und gehen vielfach als Problemfall bzw. als Objekt menschlicher Naturgestaltung in die Handlung ein - waren doch Überschwemmungen zu Jókais Lebens- und Schaffenszeit nach wie vor Alltag und die Flussregulierung Gegenstand öffentlicher Diskussionen bzw. ein Projekt, das mehrfach konkret angegangen wurde. ${ }^{8}$ So begegnet man in Zoltán Kárpáthy der fast hundert Seiten umfassenden Darstellung der großen Donaukatastrophe von 1838 und in Der neue Gutsherr einer ebenfalls detailliert beschriebenen Theißüberschwemmung, und wird im Zusammenhang mit der Theiß immer wieder auch mit Moorlandschaften bekannt gemacht. Hinzukommt der Schauplatz Banat in Der Zigeunerbaron (1885, dt. 1886) sowie das Moor von Ecsed in den Romanen Die weiße Frau von Löcse (1885, dt. 1885) bzw. Der Seelenbändiger (1888-89, dt. 1892). Es dürfen schließlich auch die fiktiven Moräste nicht außer Acht gelassen werden, die z.B. im Science-Fiction-Roman Bis zum Nordpol (1876, dt. 1891) und in der Utopie Ahol a pénz nem isten [Wo das Geld kein Gott ist] (1904) ,begangen' werden.

In all diesen Texten fällt die weiter unten mit Beispielen zu belegende Ausführlichkeit von Moor- und Flussgebietdarstellungen, bzw. Jókais Vertrautheit mit dem Problem der Entwässerung bzw. Regulierung auf. Vorerst muss aber auf seine anderweitigen Behandlungen des Themas hingewiesen werden. Jókai hat sich mit hydrografischen Fragen auch als Publizist auseinandergesetzt, wobei die dahinterstehenden Fachkenntnisse, seine Nutzung von Autoren und Periodika, bzw. von diesbezüglichen Tagesberichten im Einzelnen eher schwer zurückzuverfolgen ist. ${ }^{9}$ Charakteristisch ist jedenfalls immer wieder der Ausklang seiner Berichte. 1855 begann er seine Feuilletonreihe Életképek a mai napokból [Lebensbilder aus der Gegenwart] mit dem Feuilleton A szegedi vésznapok [Tage der Not in Szeged], in dem er von der erfolgreichen Zusammenarbeit der Szegediner bei der Anlegung von Notdämmen erzählte. Er fokussierte dabei auf die Figur eines namenlosen Mannes aus dem Volk, der die Koordinierung der Arbeiten in die Hand genommen und aus der verwirrten Masse von Stadtbewohnern ein schlagkräftiges Kollektiv organisiert hatte. ${ }^{10}$ Im zeitgleichen, Jókai zugeschrie- 
benen Hauptartikel der Vasárnapi Újság [Sonntagszeitung] wird unter dem Titel A kormányzó a tiszai árvizben [Der Gouverneur in der Theißflut] ebenfalls auf die Verantwortung und die Versäumnisse der Nation hinsichtlich der Theißregulierung eingegangen. Wobei hier Erzherzog Albrecht als Besieger der Flutwellen und - mitsamt eines Portraits - als Held der Zukunft gepriesen wird. ${ }^{11}$ Im ein Jahr späteren Lebensbild Egy nevezetes gazda honunkban [Ein namhafter Wirt unserer Heimat] wird das Jókai offensichtlich beschäftigende Dilemma kollektiver und individueller Verantwortung wieder einmal am Beispiel eines Mannes erläutert, der sein zwischen Paks und Kömlőd liegendes morastiges Gut durch eigene Kraft entwässert und in eine blühende Wirtschaft verwandelt hat. In der durch und durch stilisierten Schilderung der menschengefährdenden Moorlandschaft und der paradiesischen Nutzlandschaft hält sich der Berichterstatter mit dem Namen seines Helden Mihály Petrich solange zurück, bis er ihn zum Schluss gleichsam feierlich nennen und als einen „Patrioten von löblichem Flei $3^{\text {“12 }}$ präsentieren kann. Schon diese Gewichtung der Berichte legt nahe, dass es dem Autor nicht auf exakte Kenntnisse oder Prüfung der Situation ankommt, sondern auf publizistische und/oder literarische Nutzanwendung, wobei beides sehr leicht zusammengeht: So wie seine literarischen Texte auch als Appell bzw. als Medien des Wissens verstanden werden wollen, ${ }^{13}$ operiert auch der hydrografische Zeitungsbericht mit literarischen Mustern. ${ }^{14}$ Findet doch die Begegnung beider Textsorten im gewöhnlichen Zeitungslayout ohnedies tagtäglich als Beitrag des Jókaischen Fortsetzungsromans zu tagesaktuellen Themen (und vice versa) statt. ${ }^{15}$

Einem weiteren Beispiel dafür, wie Jókai das Fabulieren mit den exaktesten Fachkenntnissen verbindet, begegnet man in seinem fürs Kronprinzenwerk bestimmten ethnografischen Artikel Das Volksleben an der Theiß (1891). Ungeachtet dessen, dass ihm die Vorgängerartikel - János Hunfalvys Beitrag über das Stromsystem und Mihály Dékánys Artikel über die Regulierung der Theiß - das Geo- und Hydrografische ersparen, referiert er auch selbst aus diesem Bereich, indem er über die Hypothese der urzeitlichen Ost-West-Verlagerung des Theiß-Beckens berichtet, die wiederum fantastische Folgerung mit eingerechnet, der zufolge ,nach Jahrtausenden die Theiß bis zur Donau vordringen, und die dazwischen liegenden Flächen [...] nach und nach verschlingen werde, welcher Gefahr nur vorzubeugen sei, wenn das uralte Bett der Theiß, von Hußt angefangen, hinunter durch die sandige Hochebene von Deliblat bis nach Palanka wieder hergestellt werde" ${ }^{\text {"16 }}$. Dabei erwähnt er konkret den Archäologen Jenő Szentkláray und den Geografen István Hanusz, sonst belässt er es bei Hinweisen auf nicht weiter namhaft gemachte Fachgelehrte. Auch Jókais anderweitige Sekundärschriften nehmen sporadisch auf Projekte Bezug, wie die 1858 diskutierte Trockenlegung des Balatons, ${ }^{17}$ die Theißregulierung, ${ }^{18}$ und auf Akteure wie den ,genialen Ingenieur" [Anführungszeichen andersrum (66) $]^{19}$ József Beszédes, wobei der publizistische Ertrag insgesamt dennoch ärmlicher ausfällt als der literarische, bei dessen Analyse wir angekommen sind. 


\section{Diplomierte Ingenieure}

Die in diesem Kontext am deutlichsten umrissene Figur Jókais ist die Gestalt des vorbildhaften Ingenieurs - Moorkolonisators und Flussregulierers -, der sich zunächst als etwas unbeholfen, im späteren Verlauf seiner Geschichte jedoch als ein umso wertvollerer Mann der gemeinnützigen Wirksamkeit erweist. In Das namenlose Schloß (1877) ist es „Herr Doboka, der Inschellér des Komitats, beeideter Mathematikus, oder, wie die Bauern ihn nennen: mityimatyi mokus", ${ }^{20}$ der - mit dem „Blechfutteral, indem sich die topografische Karte der Herrschaft bef[indet]“ (I/85), an der Seite - „Grund und Boden aus[misst], [...] den Nebel klein[schneidet]“, und die Gewässer „zerlegt“ (I/92). Er ist es, der „während des Winters auf den gefrornen Seeen [...] die ganze Karte des Neusiedler See's und der Hansag fertig[bringt]“" (II/98). Die aufgrund dieses ,fachwissenschaftliche[n] Meisterstück[s]" (ebd.) durchgeführten und durch Doboka selbst geleiteten Arbeiten haben dann zur Folge, „daß der Neusiedler See [...] plötzlich auf allen Seiten von den überschwemmten Ackergründen zurück[tritt] und in sein altes Bett zurückkehrt[...]“ (II/99). Weitere Details der Hansag-Problematik, wie sie im Roman geschildert wird, verrät übrigens auch Jókais Quelle, die 1797 entstandene und 1815 veröffenlichte A'Fertö Tavának geographiai, historiai, és természeti leirása [Geografische, historische und natürliche Beschreibung des Neusiedlersees] von József Kis. ${ }^{21}$

Einem „Hitimatimókus“'22 von diesem Schlag begegnet man auch im Roman Die Kleinkönige (1885). Móric Mántay, der fleißige Landvermesser des Komitats weiß, welcher „Ton anzuschlagen [ist], der im Herzen des Volkes Widerhall“" (156) findet, und behauptet sich mit Erfolg, ,inmitten des Ozeans von erbosten Menschen" (155). Dadurch vermag er auch den mathematisch begabten jungen Helden des Romans, Manó Tanussy, schon früh so weit zu beeinflussen, dass dieser - entgegen dem Willen des Vaters und den Üblichkeiten seiner adligen Herkunft - zum Militäringenieur wird, ${ }^{23}$ und sich später dem ,große[n] Unternehmen der Theißregulierung“ (434) anschließt. ,[D]er göttliche Széchenyi [hat] mit der Regulierung der Theiß angefangen“, argumentiert Mántay, der den jungen Mann persönlich anheuert, und

[ich] bin nicht sehr freigebig mit solchen Titulaturen, aber wer aus Sumpfboden fruchtbare Felder macht, dem gebührt dieses Epitheton zu Recht. Ich habe die Vermessung und die Nivellierung eines Gebietes übernommen und suche mit der Laterne Menschen, wie du einer bist, und wen ich finde, den kleide ich in Samt und Seide. [...] Es ist eine garstige Arbeit, [...] [i]m Sommer bekommen wir keine gebaute menschliche Unterkunft zu Gesicht, sondern schlafen im Freien. Im Winter 
ziehen wir nach Véreskő und zeichnen dort die Karten. Wenn wir alles geschafft haben, bekommen wir eine Menge Geld, aber bis dahin leben wir von der Hand in den Mund. (485).

Zum idealisierten Charakterbild des ,,praktischen Menschen“ (482) gehört übrigens auch, dass Mántay mehrere Berufe erworben hat. Er repariert nicht nur allerlei Geräte, die man ihm bringt; auch liegen in seiner ,Blechkiste [...] das Anwalts-, das Priester- und das Ingenieurdiplom“ (527) ,säuberlich gefaltet“ (ebd.) beisammen, so dass er seinem Schützling bei dessen Ausbruch aus der ständischen Gesellschaft auch noch als Pfarrer beistehen und zu dessen nicht standesgemäßer Ehe den Segen geben kann.

Die Helden der Arbeit, und gar erst Figuren, die es trotz adliger Herkunft sind, spielen eine wichtige Rolle in Jókais Konzept der Modernisierung Ungarns. ${ }^{24}$ Unter ihnen gibt es zwei weitere Wasseringenieure, die die narrative Emanzipation dieses Figurentypus nachzeichnen. Julius Fehér rettet im Roman Verkehrte Welt (1863) seinen durch ,ständisches“ Politisieren verschuldeten Vater, indem er entgegen der gewöhnlichen Laufbahn des mittleren Adels das „Polytechnikum“ besucht, „Maschinenkonstruktion, Steinbrüche, Erdprüfungen, Luftfabrikation und andere gleich absurde Dinge“"25 lernt, um dann, während alle übrigen Güter seines Vaters verlorengehen, „die Sumpfebene zu Burjános“ (84) zu entwässern und zur neuen Lebensgrundlage seiner Familie zu machen. Interessant ist hier wieder einmal Jókais narrativer Aufbau der ihm so wichtigen Figur. Zu Beginn des Romans macht der Erzähler in einer Faschingsgesellschaft auf einen ,,[a]nspruchlose[n] junge[n] Mann“ aufmerksam: „,[V]orläufig haben wir nicht viel über ihn zu sagen“, heißt es, denn ,[e]r gehört zu den Leuten, mit welchen der Mensch hundertmal zusammenkommt, bis sie einmal auffallen. Es kann ja sein, daß es sehr tüchtige und wackere Menschen sind. Es kann ja sein, daß dies auch bei diesem der Fall ist; - nun, wir werden ja sehen.“ (13) Nach dem Bericht über die Trockenlegung des Moors von Burjános erscheint ,dieser Herr Julius“ wieder nur als ,der prosaischeste Mensch auf dieser Welt und dennoch“, so der Erzähler, „wage ich es im Vorhinein zu behaupten, daß er der Held unserer Erzählung sein wird, und daß ihn am Ende derselben Jedermann so lieb gewinnen wird, wie ich ihn bereits lieb gewonnen“ (80). Das so bekundete erzählerische Interesse führt in diesem auch ,humoristischen Roman“ genannten Werk übrigens nicht nur zur Steigerung der narrativen Wertsetzung und Perspektivierung auf diese Figur, sondern auch zu deren glücklicher Verheiratung mit der standeshöheren - da wohlhabenden - Geliebten. Ebenfalls liebgewonnen - und zwar allseitig: intraund extradiegetisch - wird schließlich auch die zweite Ingenieur-Figur, Aladar Garanay im Roman Der neue Gutsherr (1862). Der „diplomirte[...] Ingenieur“ engagiert sich ebenfalls in der ,Theißregulierungsgesellschaft" ${ }^{26}$ und leistet mit seiner Geschichte insofern einen weiteren Beitrag zu Jókais praktischen Men- 
schen, als er aus einem zur Haft verurteilten und enteigneten 1848/49-er Helden zum Schwiegersohn des ehemaligen politischen und militärischen Gegners, des pensionierten „Kürassier-Oberwachtmeisters“ (I/59) Ritter von Ankerschmidt wird. All das kann natürlich dank der Krise der Theißüberflutung und mit Hilfe der durch sie generierten Solidarität bewerkstelligt werden. ${ }^{27}$

\section{Text- und Morast-Stellen}

Wendet man sich Jókais Darstellung des Lebens in bzw. des Umgangs mit Flussund Sumpflandschaften, besonders jenen Stellen zu, in denen dies explizit zum historisch-kulturellen, lebenstechnischen Problem wird, oder gar mit landschaftsbaulichen, naturkolonisatorischen Thematiken und Exkursen verbunden wird, so lassen sich drei Schwerpunkte ausmachen. Erstens überrascht es kaum, dass bei einem Autor, der gern komplexe Romanwelten erschafft, auch Schilderungen von Fluss- und Sumpflandschaften sorgfältig ausgearbeitet werden. Hierbei lässt sich gut beobachten, wie die beschriebene Umwelt jeweils als Hindernis oder als Fluchtort ihre diegetische Funktion erfüllt. Zweitens fällt den Fluss- und Sumpflandschaften im Werk Jókais deshalb eine besondere Rolle zu, weil sie als historisch-geografische Kulisse für eines seiner Lieblingssujets bzw. -motive dienen: für das Inselleben. Und drittens sind Fluss- und Sumpflandschaften aus historisch-kulturellen Gründen auch der Schauplatz, auf dem sich Jókais Modernisierungskonzept Ungarns entwickeln lässt, wo seine nachweisliche Vorliebe für technische Entwicklung erzählerischen Raum findet. Womit man auch bei den eigentlichen Aktivitäten seiner Vorzeige-Ingenieure ankommt.

Zunächst zur Natur, als Hindernis und Fluchtort für Romanfiguren. Jókais Helden kämpfen sich durch Moore und tun dies je nachdem erfolgreich, ob sie sich dort auskennen, oder von Ortskundigen geleitet werden, und generell, wie es die Handlung und die poetische Gerechtigkeit erfordert. So wird der stark autobiografisch motivierte Ich-Erzähler der Novellensammlung Egy bujdosó naplója [Tagebuch eines Flüchtlings] (1850) durch einen Tschikosch auf morastigen Unwegen geleitet, ${ }^{28}$ und dasselbe Thema in Der Mann mit dem steinernen Herzen (1869) romanhaft verlängert: zur Flucht Ödön Baradlays nach dem verlorenen Freiheitskrieg auf einem zwischen den Flüssen Körös und Maros liegenden Sumpfgebiet. Noch abenteuerlicher gestaltet sich der ,halsbrecherische Wettlauf“ Julianna Korponays und Ritter Andernachs, des „Kurier[s] des Kanzlers“ ${ }^{“ 29}$ in Die weiße Frau von Löcse (1885). Die Bemühungen der beiden Figuren, vor der anderen vor den Palatin Pálffy in Szatmár-Németi zu treten, führen zum schleunigen Wechsel und Scheitern von Reisemitteln und -gefährten bzw. Tricks quer durch den Sumpf von Ecsed. In Das namenlose Schlo $\beta$ wird die flüchtige Marie, alias Sophie Botta, eigentlich „Princesse Marie“ ${ }^{30}$ Tochter des hingerichteten Ludwigs 
XVI. durch ,[e]in wahrhaftes Wunder Gottes [gerettet], wie deren die biblische Legende von dem rothen Meere erzählt, das dem verfolgenden Pharao den Weg verlegte" (III/119). Es geschieht nämlich, dass die Gewässer der Hansag gerade zum Zeitpunkt der Romanereignisse ansteigen und sich gegen die „starke[n] Pallisadendämme“ stemmen, die zwischen dem Moor und dem Neusiedlersee gezogen wurden, so dass „das von unten andrängende Schlammwasser da und dort ganze Hügel aus dem Torfboden zu erheben [beginnt], die wie große Geschwülste am Körper der kranken Erde aufq[ue]llen“ (ebd.). Durch den Schlamm eines solchen „Torfdurchbruch[s]“ (III/121) muss Maries Verfolger, De Fervlans, mit seiner „Dämonen-Legion“ (III/119) hindurch, und der Versuch, einen Ritter durchs „flüssige[...] Pech“ (III/120) zu schicken endet katastrophal: Er „,mühte sich [...] eine Weile inmitten des dichten, zähen Kothes ab, bis er plötzlich vor den Augen seiner Kameraden mitsammt dem Pferde unter dem schwarzen Schlammspiegel versank, der noch durch geraume Zeit einen tiefen Trichter an der Stelle bildete, wo er sein Opfer verschlungen hatte“ (III/121). Die Legion muss einen andern Weg suchen und verfehlt schließlich ihr Opfer. ${ }^{31}$

Der Blick auf die umgebende Landschaft ist bei alledem durch die für Jókai charakteristische Mischung aus malerischer und enzyklopädischer Detailtreue bestimmt. Denn in diesen Gegenden liegt viel daran, dass man sich auskennt, und der Erzähler teilt das vorausgesetzte Wissen allzu gern und ausführlich mit. Baradlays Begleiter, Gregor Boksa,

\begin{abstract}
kennt schon die Wege und Stege. [...] Zu hundert Malen hat er die Rohrlichtungen schon durchwandert. Ihm ist jede Sumpfwiese bekannt, die für das gestohlene Oechslein ein sicheres Versteck bietet. Er weiß, auf welchem Rohrbruch man die Moraststellen umgehen kann, deren Schlamm bodenlos; wo der schwankende Moorboden Roß und Reiter zu tragen im Stande ist. ${ }^{32}$
\end{abstract}

Ihm dienen, oft „,nur die schwankenden Sumpfgewächse, die Blätter des Weddegrases als Wegweiser, an denen er erk[ennt], wo das Wasser sicheren Boden hat"; er findet sich ,mit wunderbarer Orientierungsgabe [...] in der Einförmigkeit dieser Wildniß“ (IV/106) zurecht. Und gleich dem Abtrünnigen Boksa erscheint auch die Vegetation wie ,ein [...] aus der Gesellschaft Verstoßene[r]“": Auf der zur Rast dienenden Sumpfinsel

prangt der mörderische Wasserschierling, die Judenkirsche mit blutrothen Beeren, die blaublättrige giftige Geisse, der schwimmende Froschlöffel, das Schwindel erregende stinkende Sison, die betäubende Rebendolde, die finster drohende schwarze Nieswurz, wie eine aus Räubern und Mördern zusammengewürfelte lichtscheue Bande, welche hier in geheimer 
Verschwörung gegen alles Lebende ihre Vernichtungspläne auskocht. (IV/111-112) 33

Dennoch verlangt die Poetik dieser Landschaft, dass die Öde und die Zonen der Gefahr auch ihre eigene Schönheit erblicken lassen: „Ein wunderbares Bild, das zu malen sich lohnte!“, heißt es in Die weiße Frau von Löcse,

\begin{abstract}
Die Erde war so weiß, als wäre sie mit Schnee bedeckt; fingerdick lag der natronhaltige Staub darauf, in den die Sumpfvögel und die Füchse im Zickzack ihre Spuren hinterlassen hatten. Hier und dort stand auf einem kleineren Hügel eine krumme Birke, die ihre für Ruten geeigneten Äste traurig hängenließ. Das ausgedehnte Flachland war mit kleineren und größeren Tümpeln übersät, an deren Rändern Wasserliesch, Schilf und die unterschiedlichsten Arten des Sumpfschachtelhalms und des Farnkrauts prangten. Der Abendhimmel war feuerrot, sein Widerschein ließ die Pfützen purpurrot aufglänzen, und aus all diesem Rot ragten die Spießen gleichenden Blätter der Wasserpflanzen schwarz hervor. ${ }^{34}$
\end{abstract}

Wo man sich auch durchkämpft, kann man - als Held und als Leser - an solchen Stellen der Romane Jókais immer wieder innehalten und die dargebotenen (Seelen-)Landschaften bewundern.

\title{
4. Inselwelten
}

Die Moorlandschaften erlangen in Jókais Werk auch unter einem zweiten Aspekt eine besondere Bedeutung. Die von Morasten und Sümpfen umschlossenen, vor der Umwelt versteckten Orte ermöglichen den Aufbau geschützter Privaträume, die Verwirklichung einer zweiten und oft ,echten' Existenz. Dessen bekanntestes Beispiel ist die zum Doppelleben Michael Timárs dienende „herrenlose Insel“"35 - in moderner Übersetzung „Niemandsinsel“"36 - im Roman Ein Goldmensch (1872). Es handelt sich um eine in der unteren Donau, südlich der „Oßtrovaer Insel“ (I/81) befindliche „neue Alluvialbildung, von der auf den neuesten Karten noch keine Spur zu finden" (I/87) ist, und deren Entstehung sorgfältig geschildert wird. Hier findet der „erfahrene [...] Sumpf-Jäger“ (I/85) Timar nicht nur ein Naturparadies, sondern auch seine Geliebte, mit der er später - als der Gesellschaft abgewandter „Niemand“ (V/227) - sein familiäres Glück verwirklicht. Auch Manó Tanussy, Schützling des bereits zitierten Ingenieurs Mántay in Die Kleinkönige sucht sein außerordentliches - da nicht gesellschaftsfähiges - Eheglück ,auf eine[r] Insel mitten im Moor von Kurulás“"37 an der Theiß: An einem Ort, der - wie Mántay fachmännisch versichert - „kein trigonometrischer Punkt 
[ist], also [...] auch durch keinen Pfosten Aufmerksamkeit erreg[t]" (ebd.), sodass Manó seinen „häuslichen Herd [...] vor ihre[n] lieben Familie[n] sicher“ (ebd.) wissen kann. Wer weiß, so der Erzähler weiter über die Moorinsel, „,[w]ie sie wohl entstanden war? Diente sie einst Awaren oder Kumanen als Befestigung? Oder war sie die Ruhestätte gefallener Krieger, deren Leichen hier zu einem Haufen zusammengetragen worden waren? Oder war sie nur vom Meer angeschwemmt worden wie die Hügelkette bei Debrecen?" (509) Jedenfalls wird sie, so Mántay, ,in fünfzig Jahren das Zentrum eines großen Dorfes sein. Aus dem Moor ringsherum wird bester Weizenboden werden." (487) Nur noch für kurze Zeit besteht also diese „Märchenwelt“ (509), zum romantischen Glück von Helden, die hier einige, wenngleich bedeutende Tage ihres Lebens verbringen, ${ }^{38}$ sowie zum Schutz von Tieren, die der Erzähler in einer Sturmszene mit gleichsam zoologischer Leidenschaft auf diesem Hort versammelt. ${ }^{39}$

Landschaften, in denen das Leben und der Tod so nahe beieinander liegen, können freilich auch die ihnen eher angemessene Rolle spielen. Lisandra, die Heldin der glücklichen Idylle in Die Kleinkönige, ist eigentlich auf einer Insel ganz anderer Art aufgewachsen: Da ihre Mutter, Frau von Sáromberky nicht bereit war, ihr kleines Gut und Herrenhaus an Graf Adalbert Ponthay zu verkaufen, hat dieser als Besitzer des umgebenden Dominiums alles getan, um ihr den Widerstand zu verbittern. So hat er schließlich auch versucht, ,sie hinauszuekeln“: „Was nur an Spülicht durch die Gegend fließt, habe ich hierher an ihr Haus leiten lassen“, berichtet er, ,und auf der anderen Seite wurde ein Damm errichtet, damit die Brühe sich hier staute ${ }^{“ 40}$. Das hat zur Folge, dass Frau von Sáromberky mit ihrer Tochter mitten in einem „häßliche[n], eklige[n] Teich“ (12), in einem verfaulenden, von weißem Salpeter und gelbem Hausschwamm beschlagenen Haus leben muss, ${ }^{41}$ erreichbar lediglich durch eine „Klappbrücke“ (ebd) und umgeben „von einem lauen, zum Erbrechen reizenden Gestank [...], den der davon Betroffene nach Wahl für Gasgeruch oder Sumpfdünste halten durfte, vermischt mit dem Ammoniadampf von Jauche, einem tüchtigen Beitrag der Spanischen Fliegen und dem Gifthauch des Rieds" (13). Und Rache, wenngleich gerechte Rache verwandelt bereits in Jókais erstem Roman Lebenswirren (1846) das im Morast Belabora errichtete Inselparadies des krankhaften Peter Goliath Dömsödi in eine Strafinsel, auf der er nun alleine und ohne Fluchtmöglichkeiten leben muss:

Zuweilen erscheint auf der wildesten Seite der Insel, inmitten der verworrenen Maishalme eine menschliche Gestalt, ein menschliches Gespenst. [...] Er überschaut mit den glanzlosen Augen die ihn umgebende Wüste, überschaut den mit Wolken bedeckten Himmel und schaut dann in sein Inneres und findet nirgends einen Ruhepunkt, nirgends einen Hoffnungsschimmer. Himmel, Erde, eigenes Herz - all' dies ist wüst und öde. ${ }^{42}$ 
In diesem, die schwarze Romantik mit dem verblüffendsten erzählerischen Naturalismus kombinierenden Romanerstling steht selbst die hoffnungsloseste Gegend für Einklang zwischen seelischer Innen- und romanweltlicher Außenwelt, sodass der Geächtete selbst für die Aufrechterhaltung seiner Straf- und Gewissensrobinsonade sorgt: „Häufig vernimmt man an stillen Tagen und Abenden ein schmerzliches Weinen aus dem Röhricht", heißt es zum Schluss des Romans, „das langsam über die stillen Wasser dahinzieht. Die Fischer an den Ufern der Theiß halten es für das Wehgeschrei einer verdammten Seele und wagen sich nicht in die Nähe der ohnehin unwegsamen, menschenleeren Morastwildniß.“ (236) Weiterer Maßnahmen des fürs Überleben des Büßenden sorgenden Rächers, Stefan Körmös Balnai, bedarf es also gar nicht mehr.

\section{Technizität und Ästhetik}

Am wichtigsten ist im vorliegenden Zusammenhang der dritte Aspekt: Jókais literarische Auseinandersetzung mit Möglichkeiten und Konsequenzen der technischen Modernisierung. Denn es handelt sich hier um einen Autor, der ,epische Figurationen der Zusammendenkbarkeit von romantischem und kulturell-zivilisatorischem Wechsel erschafft ${ }^{\text {“43 }}$. Die Art und Weise, wie er „die technische Revolution des 19. Jahrhunderts als literarischen Gegenstand adaptiert (und nicht verharmlost)“"44 bedarf weiterer Analyse. Es stellt sich die Frage, was Jókai über die Tatsache hinaus, dass er unter seinen Vorzeigefiguren auch Wasseringenieure anführt, von deren Aktivitäten, von scheinbar literaturfernen technischen Einzelheiten und deren Wirkungen auf Menschen, Gesellschaft und Landschaft erzählt. Dessen Untersuchung ist und bleibt in literaturwissenschaftlicher Hinsicht insofern eine Herausforderung, als man sich dabei ständig auch mit der Aufgabe konfrontiert sieht, mehr als nur Beschreibungen menschlicher Naturgestaltung und technischer Apparaturen zu liefern, stattdessen auch eine Art „durchästhetisierte Technizität" ${ }^{\text {45 }}$ nachzuweisen. Man muss also auch nach Textstellen suchen, in denen das Doppel von Natur und Kultur/Zivilisation dezidiert literarisch verarbeitet, gar zum Selbstzweck, zum belastbaren Hauptproblem des Erzählers wird.

Fängt man bei dieser Suche klein an, so rücken erst einmal die je nachdem kürzeren oder längeren Textstellen in den Blick, an denen sich eine verblüffende Ausführlichkeit der Darstellung hydrologischer Umstände beobachten lässt. So umfasst der briefliche Bericht von Pfarrer Mercatoris in Das namenlose Schloß nicht nur die den Neusiedlersee und die Hansag betreffenden Geschichten und Theorien, sondern auch den Streit der Komitate über die Finanzierung und die Verantwortung des Entwässerungsprojekts. ${ }^{46}$ Desgleichen erhält der Leser in Verkehrte Welt eine über zehn Seiten lange Darstellung der Trockenlegung des Moors von Burjános. Julius Fehér „nivellierte und kalkulierte“ so lange, heißt es hier, 
„bis er endlich herausbekommen hatte, daß das Wasser der den Morast in einem Halbkreise umgebenden todten Theiß anderthalb Fuß tiefer stehe, als das Wasser des Sumpfes selbst" ${ }^{47}{ }^{47}$ Damit ist ein Rätsel aufgegeben, dessen Lösung der Reihe nach gleichsam epopeisch geschildert wird: von der Erwägung verschiedener Gründe - der Suche und der Findung von für die Stauung verantwortlichen ,eingerammte[n] Holzpflöcke[n]" (78) einer ehemaligen Avarensiedlung - bis hin zur Ausgrabung des Abwässerungskanals, die mit Hilfe erfahrener Istrianer bewerkstelligt werden muss, und zur Ausbrennung des Moors. Ein drittes Beispiel detaillierter Darstellung bietet Der neue Gutsherr, in dem das Thema der Flussregulierung von einem speziellen Problem her aufgegriffen wird, nämlich von dem der Korruption. Ein Gespräch zwischen dem zuständigen Beamten Bräuhäusel und dem vermittelnden Anwalt Dr. Grischak zeigt, wie man ein Unternehmen, wie den Schleusenbau - die Handlung spielt in den 1850er-Jahren - ,rentabel' macht: Es reicht, wenn man, die Vorschriften geschickt umgehend, kürzere Pflöcke für die Befestigung Dammes besorgt, und diese, damit es nicht auffällt, weniger tief in den Boden bettet. ${ }^{48}$ Die Folgen dieses Handels bekommen im späteren Handlungsverlauf Garanay und seine Arbeiter an den Schutzwerken der Theiß zu spüren - und zu sehen. Auf die Frage Ankerschmidts, warum man ,nicht lieber die Schleuse [fortificirt,] als das[s] man einen neuen Damm hinter ihr aufwirft", präsentiert Garanay die „hinausgeschleppten Piloten“, die weder die angeordnete Länge haben noch in die entsprechende Tiefe eingeschlagen sind und folglich für keine „Fortification von oben“ tauglich sind. „Hier hat der Unternehmer öconomisiert" (II/191), vermerkt Garanay lakonisch. Zur Ironie der Erzählung gehört auch, dass dieser Vorfall zwar später behördlich inspiziert, jedoch nicht geahndet wird. Es wird darüber hinaus auch eine andere gängige Praxis beschrieben: Ankerschmidt wundert sich darüber, dass man die Dämme auch vor Menschen und ungebetenen Besuchern schützt, und erhält als Erklärung, dass es kostengünstiger ist, ,die Schutzwerke des gegenüberliegenden Ufers zu schwächen“ (II/188-189) als die eigenen zu verstärken und dass man sich also auch gegen Sabotage zur Wehr setzen muss. In Der neue Gutsherr wird schließlich gerade eine solche Sabotage Verursacher der beschriebenen Flutkatastrophe.

Diese Beispiele erfüllen den Wunsch nach ,durchästhetisierter Technizität" nur zum Teil: Jókais Kombination von literarischem Amüsement und national-pädagogischem Engagement erlaubt es ihm sehr wohl, Fachkenntnisse und hierzu gehörende Fachtexte in den Roman zu integrieren. Er erzählt technische Details, ohne langweilig zu werden, und generiert Spannung, wo man es am wenigsten erwartet hätte. Freilich werden solche Passagen der literarischen Ökonomie untergeordnet, d.h. proportional zu anderen Sujetelementen und funktional zur Handlung eingesetzt. Deshalb muss die oben gestellte Frage dahingehend verschärft werden, ob man auch Werke Jókais findet, in denen der Teilaspekt Natur vs. Kultur/Zivilisation gleichsam zum Hauptthema und zur tragenden Struktur 
des Ganzen wird. In einigen Fällen hat dies Jókai sehr wohl umgesetzt: Von seinem Science-Fiction-Roman Bis zum Nordpol (1876) kann mit gutem Gewissen behauptet werden, dass die in ihm aufgebotenen physikalischen, geologischen, chemischen, biologischen und archäologischen Kenntnisse das Ganze deutlich dominieren und der kreative erzählerische sowie figurale Umgang mit diesen Kenntnissen den eigentlichen Gegenstand darstellt. ${ }^{49}$ Dessen konzeptueller Wert wird auch dadurch nicht gemindert, dass die Robinsonade von Peti Galiba, eines „teuflische[n] Mensch[en] des 19. Jahrhunderts“, ${ }^{50}$ am Nordpol eigentlich für das humoristische Wochenblatt Üstökös geschrieben wurde bzw. im Untertitel ursprünglich auf die „Anleitungen Jules Verne's“"51 verwies. Als ein weiterer mehr gesellschaftskritischer als humoristischer - ökonomisch-technizistischer Plot kann darüber hinaus der um Themen des Bergbaus und des Börsenlebens aufgebaute Roman Schwarze Diamanten (1870) gelesen und gedeutet werden..$^{52}$

Sucht man jedoch nach einem Werk, in dem das technische Interesse nicht nur zentral, sondern auch hydrografisch ausgerichtet ist, so lässt sich Der Roman des künftigen Jahrhunderts (1872-1874), Jókais zwischen 1952 und 2000 spielende Utopie und Science-Fiction heranziehen. Die Geschichte des erfinderischen David Tatrányi, der mit Hilfe des leichten und elastischen glasartigen Materials „Ichor" ${ }^{\text {“53 }}$ und des auf dessen Grundlage entwickelten elektronischen Flugzeugs zuerst die k.u.k.-Monarchie rettet und dann, nach zwei Weltkriegen (!), den ,ewigen Frieden" auf Erden erzwingt, ist groß angelegt zum einen hinsichtlich ihrer verblüffenden Kombination von technischer und gesellschaftlicher Utopie, ${ }^{54}$ und zum anderen bezüglich der Größenordnung der dargestellten Erfindungen bzw. Entwicklungen. Beide Aspekte erklären auch, weshalb Tatrányis Flussregulierungs- und Moorkolonisierungsprojekt auch dann besondere Bedeutung erlangt, wenn es sonst nur eines seiner Unternehmen darstellt und hinter dem „Ä̈rodromon“ (II/86), dem Flugzeug als Schlüssel aller Aktivitäten zurückbleibt. ${ }^{55}$ Gegenstand der Wasserthematik ist hier die Donau, und vor allem das zur Zeit der Handlung „im Besitze Rußlands befindliche[...] Donau-Delta“ (III/61), wohin dank eines Kriegsstreichs der bösen Madame Saßa, Regentin des russischen „Reich[s] des Nihil[s]“ (II/116) die sonst siegreiche zweihunderttausend Köpfe zählende ungarische Honvédarmee für zehn Jahre „ehrenvolle Kriegsgefangenschaft" (III/61) interniert wird. Auf diesem zuerst untröstlichen Schauplatz beschließt Tatrányi, notgedrungen und dennoch erfinderisch (wie immer), einen „Staat [...] auf Aktien“ (III/87), eine Stadt namens „Otthon (Daheim)“(III/93) zu gründen, wozu das „,von Gottes Fluch getroffene[] Land“ (III/94) zwischen den Donauarmen dreimal errungen werden muss: „Einmal vom Eigenthümer, zum zweiten vom Wasser und zum Dritten von der europäischen Diplomatie“ (III/96). Der zweite Schritt soll dabei natürlich „,in der gewöhnlichen Weise“ erfolgen: ,[M]ittelst Dämmungen, Kanälen und Pumpwerken, [u]ngefähr in derselben Manier, wie Holland mit seinen Gewässern fertig zu werden wußte. Ich werde“, sagt 
Tatrányi, „einfach die Flußarme eindämmen, die Tümpel durch Kanäle ableiten, die Moore abzapfen und wenn ich einiges Material zur Asphalt- oder Paraffin-Erzeugung in den Sümpfen finde, so werde ich es wahrhaftig auszunützen wissen.“ (III/97). Ein Plan nach Art der begabten Wasseringenieure Jókais, der diesmal freilich die gesamte Welt verändern sollte.

Der zweite Teil des Romans zeigt den Staat Otthon sieben Jahre später bereits in voller Blüte, bestehend der Reihe nach aus einer „Stadt der Gartenkultur" (III/128), einer „Stadt der Landwirthschaft“ (III/129), einer „Fabrikstadt“ (III/130) und einer „Handelsstadt“ (III/131), wobei man vor allem Letzterer und dem durch Aërodrome gesicherten Welthandel verdanken kann, dass Otthon als zweites Holland Stabilität und weltweiten Ruhm erworben hat. Die hieraus entstehenden Konflikte sowie die Machtgier der Madame Saßa ermöglichen es Tatrányi übrigens auch ein weiteres Mal, sein Talent in hydrologischen Angelegenheiten zu zeigen: Der wiederholten Besetzung Ungarns durch Russland und assoziierte Kriegskräfte und dem Angriff gegen Otthon wird durch einen „Kampf [...] mit Wasser" (IV/130) Widerstand geleistet: Der mit der Regulierung des Eisernen Tores betraute Tatrányi versperrt den Donaupass durch einen speziell hierfür entwickelten mobilen Staudamm, mit der Folge, dass die zurückfließenden Wassermengen - deren Weg zurück ins Land wiederum detailliert beschrieben wird - jede weitere kriegerische Aktivität verhindern:

Der Feldzug in Südungarn war nunmehr auch schon zu Ende. [...] Zwischen Ungarn und Serbien war ein Meer gelegt, dessen Gestade einerseits von Ogrodina bis Agram die serbische Bergkette bildete, während jenseits seine Wogen bis an die Telecskaer Höhen flutheten, den Fuß des Weingebirges der Baranya bespülten und gegen Osten hin bis an die Hügel um Vinga keine Grenze fanden. Eine einzige langgestreckte Insel ragte aus diesem Meere hervor: die Syrmier Bergkette in Slavonien und die Gruppe des schwarzen Berges in Kroatien. Alles Übrige ist ein Reich der Wellen. Von dieser Seite war Ungarn unangreifbar gemacht. (IV/155)

Mit diesem Kunststück der richtungsverkehrten Flussregulierung - der planvollen Deregulierung - wird in Der Roman des künftigen Jahrhunderts nichts weniger als die Herbeiführung des ewigen Friedens eingeleitet. Nimmt man das Vorwort des Romans als Paratext ernst, so will dieser tatsächlich mehr als ein produktives und recht vergnügliches Spiel mit der Einbildung. Jókai verbindet die „Erkenntnis“ - nämlich die Prüfung historischer Grundlagen und Möglichkeiten - programmatisch mit dem „Glauben“, dass die Technik der Zukunft - konkret: das Fliegen - nicht leere „Phantasie“ (I/2), sondern die Lösung von Problemen werden würde, deren inventarische Aufzählung er ernsthaft vornimmt (I/6-9). 
Wenn dann im Roman stellenweise der Verdacht aufkommt, dass man mit Übertreibung, gar Parodie, sei es die der Doppelmonarchie, ${ }^{56}$ sei es Vernescher Art, zu tun hat, so mündet der Romanschluss dennoch in ein das Vorwort bekräftigendes technisch-utopisches Finale. Insofern kann dem Werk mehr als eine bloß literarische Wirkungsabsicht zugesprochen werden. Der Roman erfüllt den Auftrag, eine wünschenswerte und sogar nicht unmögliche Zukunft vorwegzunehmen. Das Kunstwerk des neunzehnten Jahrhunderts avanciert zum Stellvertreter der Techné des zwanzigsten Jahrhunderts. Jókais Roman versucht dies thematisch, aber auch allegorisch, als ,Werk', umzusetzen. Das Geschick, das dazu gehört, eine Vision von diesem Format zu erschaffen, d.h. ein Flugzeug und zahlreiche andere Technologien fürs menschliche Wohl literarisch zu erfinden, verspricht Größeres und - die Verwirklichung. Die Wertschätzung, die der Roman ihren (technischen) Themen gegenüber artikuliert, begreift auch deren Bilder in sich. „Diese veränderte Landschaft ist das schönste Gedicht und wer es dichtete und zu Stande zu bringen vermochte, ist das poetischste Gemüth“ (84), ${ }^{57}$ heißt es über die Entwässerung des Moors von Burjános durch Julius Fehér im Roman Verkehrte Welt. Das bedeutet, dass die Entwässerung (ein an sich prosaisches Thema) kunstvoll (statt nur planvoll) und als solche ,schön“ werden kann. Gerade dieses Lob gebührt Jókais Vorwort des Romans des künftigen Jahrhunderts zufolge auch jedem literarischen Text, wenn in ihm und durch ihn Projekte zum allgemeinen Wohl fiktiv umgesetzt bzw. die Leistungen des menschlichen Könnens stellvertretend demonstriert werden.

Wo das literarische Können für Kulturlandschaften (bzw. für Modernisierung im Allgemeinen) konkret und allegorisch einsteht, und umgekehrt, die menschliche Naturgestaltung Literatur ermöglicht, öffnet sich schließlich auch Raum für Selbstkritik. Der autobiografisch motivierte Erzähler von Jókais spätem Ein bejahrter Mann ist kein alter Mann. Erträumter Roman in vier Abteilungen (1900) versetzt sich in alternative Lebensgeschichten, darunter - in der zweiten Geschichte - in die Rolle eines erfolgreichen Wasseringenieurs, der nicht nur einen ,Aquaeduct“ baut, der Budapest mit Quellwasser ,,vom Abhang der Bükk“58 versorgt, nicht nur den „Theiß-Donau-Kanal, eine[n] der größten des Kontinents“ (57) errichtet, sondern auch ,[e]in gigantisches Unternehmen“ ins Leben ruft: eine internationale Aktiengesellschaft für den Bau des ,große[n] Karstkanal[s]“, der „die Donau mit dem adriatischen Meer verbinden“(76) sollte. Das Problem ist nur, dass es eigentlich bei allen diesen (utopischen) Großprojekten - wie übrigens in allen vier Episoden des Romans - um etwas ganz anderes geht. Alles dreht sich um die Heirat mit einer viel jüngeren Frau, als ein ebenfalls ,gigantisches Unternehmen'. Genauso freilich, wie das Heiratsprojekt scheitern muss, endet auch das Kanalprojekt mit einem Desaster. Die ironische Tonlage und deutliche paratextuelle bzw. metafiktionale Bezugnahmen des Erzählers auf Jókai als Autor bringen dabei auch ein drittes Projekt, das literarische Schaffen mit ins Spiel und setzen es 
zugleich einem Verdacht aus: Sie deuten an, dass die technischen Träume eng mit dem Wahnsinn verwandt sind, und dass sich Romane, die die Zukunft verkünden, der Gefahr der Lächerlichkeit aussetzen. Man kann von der Utopie wie von einer jungen Frau betrogen werden und bei allem Talent auch literarisch ,Bankrott gehen ${ }^{6}{ }^{59}$ Hier ist also Besinnung geboten, deren sich Jókais später Roman durchaus bedient. Er demonstriert, dass die Selbsthinterfragung in der Literatur grundsätzlich möglich und auch schmerzfreier ist, als im Leben selbst. Womit eine der wichtigsten Eigenschaften literarischer (Fluss- und Sumpf-)Landschaften und der Arbeit an ihnen ausgesprochen ist. Die Romanpoetik des ganz und gar Prosaischen, wie Jókai sie umsetzt, kann im Dienst der Volkserziehung stehen, kann große Menschheitsträume thematisieren, sie kann aber auch, wie das letzte Beispiel belegt, auf den Sinn der (Tendenz-)Literatur überhaupt zurückkommen und die eigene Zuständigkeit in Frage stellen. Das späte Werk rundet insofern die Aufbruchsstimmung jener Romane, die hier vorgestellt wurden, lakonisch und etwas verspielt, und dennoch ihr Engagement widerspiegelnd, mehr, weise' als enttäuscht wieder ab.

\section{Anmerkungen}

1 Einige Titel, die später nicht zitiert werden: Nagy, Miklós: Zwei hundertjährige Jókai-Romane: „Ein ungarischer Nabob“ und „Zoltán Kárpáthy“. Budapest 1957 (Sonderdruck aus: Annales Universitatis Scientiarum Budapestinensis de Rolando Eötvös nominatae, Sectio philologica); Szajbély, Mihály: Die strukturbildende Rolle der Stereotypen im Rijeka-Roman von Maurus Jókai Ein Spieler, der gewinnt (1882). In: Horváth, Géza/Bombitz, Attila (Hrsg.): „Die Wege und die Begegnungen“. Festschrift für Károly Csúri zum 60. Geburtstag. Budapest: Gondolat 2006, S. 302-312; Gángó, Gábor: Zwischen Nationalismus und künstlerischer Immanenz: Die Romandichtung Mór Jókais aus der Sicht der ungarndeutschen Presse (Nachwort). In: Ujvári, Hedvig: Kulturtransfer in Kakanien. Zur Jókai-Rezeption in der deutschsprachigen Presse Ungarns (1867-1882). Berlin: Weidler 2011, S. 227-240; Hárs, Endre: „Emma“ alias „Emanuel“. In Geschlechterrollen kreuz und quer durch „Jókai-Ungarn“. In: Millner, Alexandra/Teller, Katalin (Hrsg.): Transdifferenz und Transkulturalität. Migration und Alterität in den Literaturen und Kulturen Österreich-Ungarns. Bielefeld: Transcript 2018 (=Lettre), S. 97-113.

2 Fábri, Anna: Jókai-Magyarország. A modernizálódó 19. századi magyar társadalom képe Jókai Mór regényeiben [Jókai-Ungarn. Bild der modernen ungarischen Gesellschaft des 19. Jahrhunderts in Mór Jókais Romanen]. Budapest: Skíz 1991.

3 „Jókai ist eine ganze, glückliche Welt, voll mit Millionen von Figuren und Farben, von Glanz und naivem, unwiderstehlichem Zauber. In seiner kosmischen Weite und Fülle lebt der ungarische Globus, noch in chaotischem Nebel zwar, aber mit so viel Begeisterung fürs Leben, mit der man nichts vergleichen kann. Jókai ist die ungarische Luft“ - schreibt Móricz (ironisch, wie übrigens fast Alle in der literarischen Nachfolgegeneration). Móricz, Zsigmond: Jókai. Jegyzetek a belső fejlődés történetéhez [Jókai. Anmerkungen zur Geschichte der inneren Entwicklung] [1922]. In: Ders.: Tanulmányok [Studien] I. Budapest: Szépirodalmi 1978, S. 425-439, hier 439. (Die Übersetzungen, falls nicht anders vermerkt, von mir. E.H.); Vgl. auch „JókaiWelt"“, ebd., S. 427. 
4 Vgl. Ujvári, Hedvig: Kulturtransfer in Kakanien. Zur Jókai-Rezeption in der deutschsprachigen Presse Ungarns (1867-1882). Berlin: Weidler 2011, S. 74-86.

5 Fábri: Jókai-Magyarország, S. 27, S. 239-241. Szajbély interpretiert die mythischen und/oder märchenhaften Wertekonstellationen der Jókai-Romane als symbolische Strukturelemente, deren Bedeutsamkeit erst im Hinblick auf die undurchsichtig gewordene moderne Lebenswelt, durch Heranziehung außertextueller und - in Hinsicht der zeitgenössischen Ästhetik - a-kanonischer Literaturbezüge voll klar wird. Szajbély, Mihály: Jókai Mór (1825-1904). Pozsony [Bratislava] 2010 (=Magyarok emlékezete), S. 43-55, 119, 193.

6 Veress spricht in seinem „Brevier“ naturwissenschaftlicher Textstellen Jókais von der Idee eines ,neuen Bildungsmodells”, das der Autor vorwiegend auf die Naturwissenschaften gründen wollte. Veress, Zoltán: Jókai természettudománya [Jókais Naturwissenschaft]. Bukarest: Kriterion 1977 (=Téka), S. 7, S. 10.

7 Die Daten der deutschen Fassungen beziehen sich immer auf die erste Buchausgabe und richten sich nach Fazekas, Tiborc: Bibliographie der in selbstständigen Bänden erschienenen Werke der ungarischen Literatur in deutscher Übersetzung (1774-1999). Hamburg: Eigenverlag des Verfassers 1999.

8 Im Überblick: Károlyi, Zsigmond: A vízhasznosítás, vízépítés és vízgazdálkodás története Magyarországon [Geschichte der Wassernutzung, des Wasserbaus und der Wasserwirtschaft in Ungarn]. Budapest 1960. Fodor, Ferenc: Magyar vízimérnököknek a Tisza-völgyben a kiegyezés koráig végzett felmérései, vízi munkálatai és azok eredményei [Messungen, Bauprojekte und Arbeitsergebnisse ungarischer Ingenieure im Theißtal bis zur Epoche des Ausgleichs]. Budapest: Tankönyvkiadó 1957.

9 Jókai gehörte prinzipiell zu den naturwissenschaftlich interessierten und hiervon literarisch profitierenden Autoren seiner Zeit. Vgl. Veress, Jókai természettudománya. Der Katalog von Jókais Bibliothek weist zahlreiche Werke zur Geologie, Naturgeschichte und Länderkunde nach, jedoch keine Titel zur hydrografischen Literatur der Zeit. Vgl. Csorba, Csilla E. (Hrsg.): „Egy ember, akit még eddig nem ismertünk". A Petőfi Irodalmi Múzeum Jókai-gyüjteményének katalógusa [„Ein Mensch, den wir bisher nicht kannten”. Katalog der Jókai-Sammlung des Literaturmuseums Petőfi]. Budapest: PIM 2006. Die regelmäßige Lektüre einiger Fachzeitschriften ist nachweisbar. Vgl. JóKAI, Mór: A jövő század regénye [Roman des künftigen Jahrhunderts] (1872-1874). Jókai Mór Összes Művei [Mór Jókais Sämtliche Werke] (im Weiteren zitiert als JMÖM) Regények [Romane] 18. Budapest: Akadémiai 1981, S. 605. (Kommentarteil).

10 Jókai, Mór: Életképek a mai napokból I. A szegedi vésznapok. In: JMÖM Cikkek és beszédek [Feuilletons und Reden] 4. 1850-1860. I. Budapest: Akadémiai 1968, S. 147-151.

11 Jókai, Mór: A kormányzó a tiszai árvízben. In: JMÖM Cikkek és beszédek 4, S. 679-680. Zur Abbildung vgl. N.N.: A kormányzó a tiszai árvizben. Vasárnapi Újság. 13.05.1855, S. 145. http://epa.oszk.hu/00000/00030/00063/pdf/VU-1855_02_19_05_13.pdf [03.05.2019]

12 Jókai, Mór: Életképek a mai napokból. Egy nevezetes gazda honunkban. In: JMÖM Cikkek és beszédek 4, S. 180-185, hier S. 185.

13 Zu Jókais Konzept und Praxis des Tendenzromans vgl. Szajbély, Jókai Mór (1825-1904), S. 68-71.

14 So ist z.B. der Zusammenhang zwischen dem Vorbild Mihály Petrich und dem Moorkolonisator Gyula Fehér im Roman Verkehrte Welt bis in den Wortlaut rekonstruierbar.

15 Zum Feuilletonroman am Beispiel Jókais vgl. Hansági, Ágnes: Romanphilologie = Buchphilologie? In: Kelemen, Pál/Kulcsár Szabó, Ernő/Tamás, Ábel (Hrsg.): Kulturtechnik Philologie. Zur Theorie des Umgangs mit Texten. Heidelberg: Winter 2011, S. 429-451; Szajbély: Jókai Mór (1825-1904), S. 148-157, S. 191-201.

16 Jókai, Maurus: Das Volksleben an der Theiß. In: Die österreichisch-ungarische Monarchie in Wort und Bild. Auf Anregung und unter Mitwirkung [...] des durchlauchtigsten Kronprinzen 
Erzherzog Rudolf [...]. Ungarn. Band II. Wien: Druck und Verlag der kaiserlich-königlichen Hof- und Staatsdruckerei 1891, S. 36-57, 41.

17 Vgl. Jókai, Mór: A magyar Tempevölgy. Regényes tájleírás [Das ungarische Tempe-Tal. Romantische Landschaftsbeschreibung]. In: JMÖM Cikkek és beszédek 5, 1850-1860 II, S. 5470, hier S. 58. In den Anmerkungen der historisch-kritischen Ausgabe wird auch die (wenngleich kritische) Kenntnisnahme von Jókais Artikel in der genannten Diskussion vermutet. Vgl. ebd. S. 495.

18 Vgl. Jókai, Mór: A magyar irodalom missiója [Die Mission der ungarischen Literatur]. In: JMÖM Cikkek és beszédek 4, S. 421-435, hier S. 429. Vgl. auch S. 834, einen zeitlich nahe liegenden Bericht aus der Magyar Sajtó [Ungarische Presse ].

19 In seinem More Patrio. Regényes kóborlások [More Patrio. Romantische Wanderungen] (1858) berichtet Jókai nicht nur über Beszédes' Verdienste, sondern teilt auch eine Anekdote über ihn mit. In: JMÖM Cikkek és beszédek 5, S. 133-169, hier S. 144-145. Vgl. JMÖM Följegyzések [Aufzeichnungen] I. Budapest: Akadémiai 1967, S. 231.

20 Jókai, Maurus: Das namenlose Schloß. Roman. o. Ü. 3 Bde. Berlin: Verlag von Otto Janke 1879, Bd. I, S. 92. Die Volksetymologie „mityimatyi mokus“ geht auf „hites matematikus [beeideter Mathematikus]", die historische Bezeichnung des Landvermessers zurück. Bei wiederholten Zitationen derselben Quelle werden Band und Seitenzahlen im Haupttext angeführt.

21 Kis, József: A’ Fertő Tavának geographiai, historiai, és természeti leirása. 1797-ben. Kis Jósef Orvos Doctor által. In: Monumenta Hungarica, az-az: magyar emlékezetes Irások. Első kötet [Monumenta Hungarica, oder Ungarische Memoirs. Erster Band]. Hrsg. v. Károly György Rumy. Pest: Trattner 1817, S. 337-423. Mehrere Stellen sind sogar identisch, wie z.B.: ,Jener Kanal allein, welcher den Königssee mit der Rabcza verband, machte das Wasser des Neusiedler See's so rasch ablaufen, daß, als der ganze Moorgrund der Hansag sich plötzlich mit seiner ganzen Masse senkte, auf den Wiesen Springbrunnen in Mannesdicke zum allgemeinen Erstaunen in allen Richtungen in die Höhe schnellten." Das namenlose Schloß, S. II/99, bei Kis S. 414. Dobokas Vorbild ist wahrscheinlich der von Kis ausführlich zitierte János Hegedüs. Vgl. ebd. S. 360-368. Zu weiteren Anleihen Jókais vgl. Das namenlose Schloß, S. II/95-97.

22 Jókai, Mór: Die Kleinkönige. Roman. Übers. v. Bruno Heilig. Leipzig: Paul List [1965], S. 53.

23 Er tut dies erst nach einem gescheiterten Versuch zum Prediger - zu einer Laufbahn, die für 'Jókai-Ungarn' viel zu traditionsbelastet ist.

24 Vgl. Fábri, Jókai-Magyarország, S. 164-174.

25 Jókai, Maurus: Verkehrte Welt. Roman. o. Ü. Berlin: Otto Janke 1884, S. 71.

26 Jókai, Maurus: Der neue Gutsherr. Humoristischer Roman in zwei Bänden, aus der Zeit der Bach-Hußaren in Ungarn 1849-1859. Dresden:Wallersteinsche Buchhandlung 1876, Bd. II, S. 88.

27 „Und es wäre nie geschehen, daß Sie einander kennen lernten, würde die zerstörende Fluth sie nicht auf eine kleine Insel zusammengetrieben haben. - Bei der Rückkehr fand Aladar das Wasser nicht mehr so schmutzig als bisher." Ebd., S. II/263.

28 Jókai, Mór: Egy bujdosó naplója. In: JMÖM Elbeszélések [Erzählungen] (1850) 2/B. Budapest: Akadémiai 1989, S. 5-146, hier S. 22-34. Vgl. auch Ders.: A végzet kezdete s a kezdetnek a vége [Anfang des Endes und des Anfangs Ende]. In: Ders.: Politikai divatok [Politische Moden] (1862-63). JMÖM Regények [Romane] 14. Budapest: Akadémiai 1963, S. 160-171.

29 Jókai, Mór: Die weiße Frau von Löcse. Historischer Roman. Übers. v. Georg Harmat. Leipzig/ Weimar: Gustav Kiepenheuer 1985, S. 339.

30 Jókai: Das namenlose Schloß, S. III/176.

31 Den Rest gibt den Verfolgern der „Fischmensch“ Hanczi Istok - der Waisenknabe, der „in die Sümpfe der Hansag gerathen, und dort unter den wilden Thieren selbst zum wilden Thiere geworden“ (I/196) war. Er setzt - das von De Fervlans erlernte Kunststück mit dem Feuerzeug 
wiederholend - das umgebende Röhricht in Brand und zerstreut die Dämonen endgültig in alle Welt.

32 Jókai, Maurus: Der Mann mit dem steinernen Herzen. Roman. Aus dem Ungarischen. Autorisierte Übersetzung, o. Ü. 4 Bde. Berlin: Otto Janke 1875, Bd. 4, S. 105.

33 In moderner Übersetzung: „,er mörderische Wasserschierling, die giftige Hundspetersilie mit ihren blauen Blättern, das Froschkraut, die heimtückische Schlangenwurz, die unheimlich schwarze Nieswurz, der betäubend riechende Sumpfporz". Jókai, Mór: Die Baradlays. Roman. Übers. v. Bruno Heilig. Leipzig: Verlag Neues Leben 1958, S. 445.

34 Jókai, Die weiße Frau von Löcse, S. 341.

35 Jókai, Maurus: Ein Goldmensch. Roman. Aus dem Ungarischen. Autorisierte Übersetzung. Deutsch herausgegeben von einem Landsmanne und Jugendfreunde des Dichters. o. Ü. 5 Bde. Berlin: Otto Janke 1873, Bd. 1, Inhaltsverzeichnis.

36 Jókai, Mór: Ein Goldmensch. Übers. v. Henriette Schade-Engl. Budapest: Corvina 2001 (1964), S. 48.

37 Jókai: Die Kleinkönige, S. 487.

38 Manó Tanussy beteiligt sich schließlich in Amerika ,am Bau der Pacific-Bahn und an dem Fortschritt der Elektrotechnik“" (578) und versorgt seine mittellos gewordenen Eltern in Ungarn mit anonymen Geldspenden.

39 Vgl. ebd., S. 509-515. Die Szene enthält auch einen Kampf mit Wölfen - mit der Rettung der gejagten Büffelkuh für die kleine Hauswirtschaft.

40 Jókai: Die Kleinkönige, S. 15.

41 Frau von Sáromberky, selbst eine „Klatschbase“ (14) und Hochstaplerin, hat dazu einen sprechenden Namen. ,Sár(om)berek' bedeutet ,Sumpfhain“.

42 Jókai, Maurus: Lebenswirren. Übers. v. Ludwig Wechsler. Berlin: Otto Janke [1886], S. 229230.

43 Fried, István: Jókai Mór és a világirodalom [Mór Jókai und die Weltliteratur]. In: Hansági, Ágnes/Hermann, Zoltán (Hrsg.): „Mester Jókai“. A Jókai-olvasás lehetőségei az ezredfordulón [Meister Jókai. Möglichkeiten der Jókai-Lektüre um die Jahrtausendwende]. Budapest: Ráció 2005, S. 13-31, hier S. 17.

44 Ebd.

45 Ebd., S. 18.

46 Vgl. Jókai: Das namenlose Schloß, S. II/95-98.

47 Jókai: Verkehrte Welt, 76.

48 Jókai: Der neue Gutsherr, S. I/135.

49 Vgl. Hárs, Endre: Motivierung und Raumnarratologie. Mit einer Modellanalyse von Maurus Jókais Bis zum Nordpol! (1876). In: Horváth, Márta/Mellmann, Katja (Hrsg.): Die biologischkognitiven Grundlagen narrativer Motivierung. Münster: Mentis 2016 (Poetogenesis. Studien und Texte zur empirischen Anthropologie der Literatur 10), S. 129-149.

50 Jókai, Mór: Bis zum Nordpol. Ein klassischer Science-Fiction-Roman. Übers. v. Hans Skirecki. Berlin: Verlag Das Neue Berlin 1989, S. 145.

51, , $[\mathrm{N}]$ ach den Anleitungen Jules Verne's ans Licht gebracht“ lautet der Untertitel im Pester Lloyd. Die deutschsprachige Veröffentlichung erfolgte 1875 parallel zur ungarischen im $\ddot{U}_{s}$ tökös. Vgl. Jókai, Mór: Egész az északi pólusig! In: Ders.: Egy ember, aki mindent tud. [Ein Mensch, der alles weiß] JMÖM Kisregények [Kleinromane] 2. Budapest: Akadémiai 1976, S. 520 (Kommentarteil). Trotz des ironischen Gestus knüpft Jókai hier auch explizit an die Anfänge der Science-Fiction und das Genre, Jules Verne ‘ an. Vgl. Innerhofer, Roland: Deutsche Science-Fiction 1870-1914. Rekonstruktion und Analyse der Anfänge einer Gattung. Wien/ Köln/Weimar: Böhlau 1996 (=Literatur in der Geschichte - Geschichte in der Literatur 38), S. 29-84. 
52 Jókai, Maurus: Schwarze Diamanten. Übers. v. Eduard Glatz. Pest: Athenaeum 1871. Auch Berlin: Otto Janke 1877.

53 Jókai, Maurus: Der Roman des künftigen Jahrhunderts. o.Ü. 4 Bde. Preßburg/Leipzig: Carl Stampfel 1879, Bd. I, S. 175.

54 Dies unterscheidet ihn von den Romanen Jules Vernes. Vgl. Jókai: A jövő század regénye, S. 607 (Kommentarteil).

55 Zum kartografischen Blick Jókais vgl. Király, Edit: Süsswasser- und Felsenmeere. Wunderbare Geografien im Roman des künftigen Jahrhunderts von Maurus Jókai. http://www.kakanien. ac.at/beitr/emerg/EKiraly3.pdf [03.05.2019].

56 Vgl. Kovács, Henriett: Zwei Zukunftsbilder des ewigen Friedens in Österreich-Ungarn. Bertha von Suttner und das utopische Maschinenalter - Mór Jókai und der satirische Roman des künftigen Jahrhunderts. In: Lughofer, Johann Georg/Pesnel, Stéphane (Hrsg.): Literarischer Pazifismus und pazifistische Literatur. Bertha Suttner zum 100. Todestag. Würzburg: Königshausen\&Neumann 2016, S. 147-161.

57 In einer anderen Übertragung: „Diese verwandelte Gegend ist die schönste Dichtung, und wer sie erdacht und sie zu verwirklichen wußte, ist das poesiereichste Gemüth gewesen." In: Jókai, Maurus: Tollhäuslerwirthschaft. Humoristischer Roman. Nach der zweiten Ausgabe des Originals aus dem Ungarischen übersetzt von einem Landsmanne und Jugendfreunde des Dichters. [Übers. v. Karl-Maria Kertbeny]. 2 Bde. Berlin: Otto Janke 1873, Bd. I, S. 179.

58 Jókai, Maurus: Ein bejahrter Mann ist kein alter Mann. Erträumter Roman in vier Abteilungen. Übers. v. Dr. Béla Diósy. Wien/Budapest: Spielhagen\&Schurich/Sachs\&Pollak 1900, S. 56.

59 Es ist bekannt, dass Jókai pragmatisch genug war, seine Romanproduktion immer auch als Gelderwerb zu betrachten. Vgl. Szajbély: Jókai Mór (1825-1904), S. 283-290.

Open Access. This is an open-access article distributed under the terms of the Creative Commons Attribution 4.0 International License (https://creativecommons.org/licenses/by/4.0), which permits unrestricted use, distribution, and reproduction in any medium, provided the original author and source are credited, a link to the CC License is provided, and changes - if any - are indicated. (SID_1) 